\title{
FIRST RF TEST AT 4.2K OF A 200MHZ SUPERCONDUCTING NB-CU CAVITY*
}

\author{
R.L. Geng ${ }^{\dagger}$, P. Barnes, D. Hartill, H. Padamsee, J. Sears, LEPP, Cornell Univ., Ithaca, NY 14853, USA \\ S. Calatroni, E. Chiaveri, R. Losito, H. Preis, CERN, Geneva, Switzerland
}

\section{Abstract}

A $200 \mathrm{MHz}$ single cell elliptical $\mathrm{Nb}-\mathrm{Cu}$ cavity has been fabricated and tested at $4.2 \mathrm{~K}$ and at $2.5 \mathrm{~K}$ in a vertical dewar fitted in a radiation shielded pit, $5 \mathrm{~m}$ deep and $2.5 \mathrm{~m}$ in diameter. The low field $Q_{0}$ reached $1.5 \times 10^{10}$ at $4.2 \mathrm{~K}$. Two multipacting barriers show up at $E_{a c c}=3 \mathrm{MV} / \mathrm{m}$ and $1 \mathrm{MV} / \mathrm{m}$. Helium processing is effective to reduce field emission and improve accelerating gradients by a factor of as much as $2 . E_{a c c}$ reached $11 \mathrm{MV} / \mathrm{m}$ at a $Q_{0}$ of $6 \times 10^{8}$. The Q-drop is observed but shows a stronger field dependence as compared to expected Q-slope typical for $\mathrm{Nb}-\mathrm{Cu}$ cavities.

\section{INTRODUCTION}

The proposed neutrino factory and muon collider ask for RF cavities operating at a frequency near $200 \mathrm{MHz}$ for rapid acceleration of muons [1]. One scenario is to use superconducting RF cavities [2]. The desired accelerating gradient is at least $15 \mathrm{MV} / \mathrm{m}$ at a $Q_{0}$ of $6 \times 10^{9}$. Since there is no superconducting RF experience at $200 \mathrm{MHz}, \mathrm{R} \& \mathrm{D}$ in this regime should be started early. Cornell and CERN collaborated to fabricate and test of a $200 \mathrm{MHz}$ single cell elliptical $\mathrm{Nb}-\mathrm{Cu}$ cavity.

\section{FABRICATION}

The prototype cavity is fabricated at CERN with the standard film niobium sputtering technique that has been used for manufacture of LEP2 cavities. Due to its gigantic dimensions at such a low frequency, it would have been too expensive and inefficient to build the $200 \mathrm{MHz}$ cavity with bulk Niobium. The shape of the prototype cell is the result of a trade-off between the optimization of RF parameters $\left(E_{p k} / E_{a c c}, B_{p k} / E_{a c c}, R / Q\right)$ and the geometry imposed by the requirements for film deposition of Niobium using the technique of DC Magnetron Sputtering. The diameter of the cell measures $1370 \mathrm{~mm}$, while the diameter of the cut-off tubes is $400 \mathrm{~mm}$. The ratio between these diameters is higher than usual to reduce the risk of leak problems at the end flanges. The consequences are a higher R/Q but also a higher value for the ratio of $E_{p k} / E_{a c c}$. On the other hand having the possibility of enlarging the radius gives more flexibility to optimize the shape for sputtering, and a next version of the cavity should certainly address such a problem. RF parameters are listed in Table 1.

\footnotetext{
${ }^{*}$ Work supported by NSF

†rg58@ cornell.edu
}

Table 1: RF parameters

\begin{tabular}{|c|l|c|}
\hline Parameter & Value & Unit \\
\hline $\mathrm{G}$ & 250 & $\Omega$ \\
$\mathrm{R} / \mathrm{Q}$ & 121 & $\Omega$ \\
$E_{p k} / E_{a c c}$ & 1.69 & - \\
$B_{p k} / E_{a c c}$ & 4.34 & $\mathrm{mT} /(\mathrm{MV} / \mathrm{m})$ \\
$E_{a c c} / \sqrt{U}$ & 0.518 & $(\mathrm{MV} / \mathrm{m}) / \sqrt{J}$ \\
\hline
\end{tabular}

Once the geometry has been fixed, the minimum thickness to avoid collapse under the atomspheric pressure has been calculated by simulating the structure with ANSYS. The two half cells were formed by spinning two $8 \mathrm{~mm}$ thick OFE copper sheets. We removed electrolytically $400 \mu \mathrm{m}$ from the surface to reduce the imperfections induced by the mechanical process. The cavity was then welded by ACCEL with an electron beam from the inside, to avoid welding projections inside the cavity. Further mechanical smoothing has been done at CERN by grinding locally all the sharp points of the internal surface. Chemical polishing (SUBU) was performed twice on the whole cavity to remove $20 \mu m+20 \mu m$, the standard value to prepare the copper surface before the deposition of the niobium film. Fig. 1 shows the photo of a half cell under rinsing.

The deposition was made by using the existing infrastructure of the LEP2 cavities. The cavity was rinsed at 100 bars with ultra pure water on the automatic programmable machine. A special vacuum valve was installed on the cavity to insulate the cavity from the outside after drying the cavity. The cavity, filled with dry and dust-free N2, was then sent by airplane and truck to LEPP.

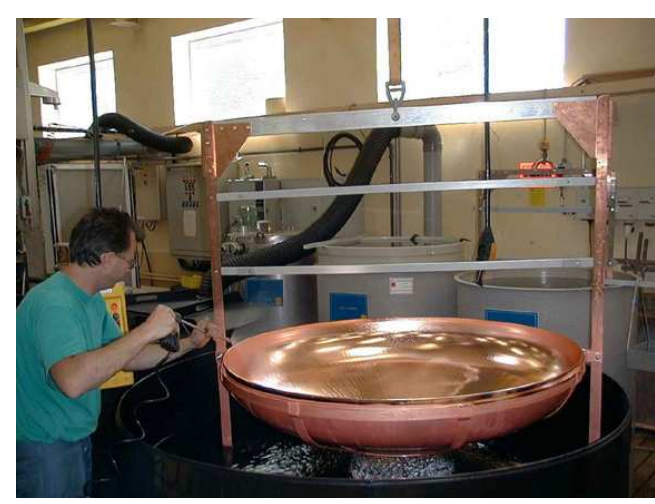

Figure 1: A half cell that is being rinsed. 


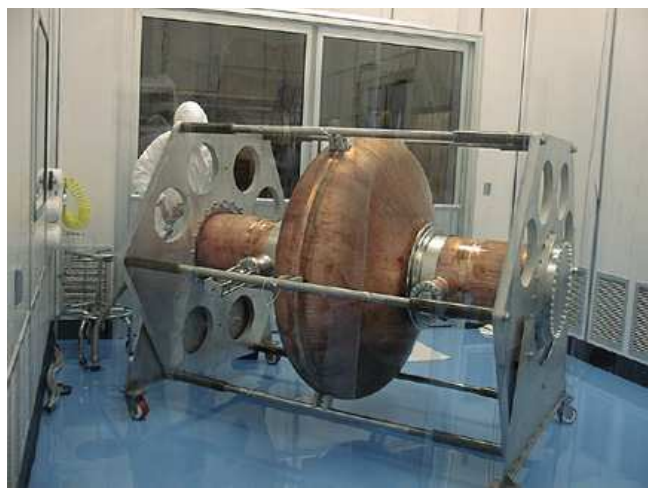

Figure 2: 200MHz cavity on a horizontal supporting frame.

\section{PREPARATION}

After arriving at LEPP, the cavity was rolled into the clean room for installation of the input coupler and for pump down. Fig. 2 shows a photo of the cavity when it was in the clean room.

Facilities at LEPP have been upgraded to allow vertical tests of this $2 \mathrm{~m}$ long cavity. A 72 inch diameter dewar, manufactured by Cryofab, is fitted into a pit of $5 \mathrm{~m}$ deep and $2.5 \mathrm{~m}$ in diameter. The pit is lined with low-carbon steel sheets and the earth magnetic field is attenuated to 200 mGauss. The radiation from the test pit is shielded by an 80-ton movable block. Up to $2 \mathrm{~kW}$ RF power (CW) at $200 \mathrm{MHz}$ range is available from a solid state amplifier manufactured by QEI. High power RF cables are all fitted with LC connectors or $7 / 8^{\prime \prime}$ flanged coax connectors. The $2 \mathrm{~kW}$ input coupler, manufactured by Ceramaseal, is fitted with a bellow allowing an adjustable $Q_{\text {ext }}$ (from $10^{9}$ to $10^{10}$ ). Fixed couplers (connector DN16 type 7/16) rated at $500 \mathrm{~W}$, obtained from CERN, are also used. A new 200 $\mathrm{MHz}$ RF electronics system was built. Home molded foam (Versi-Foam from RHH Foam System) blocks are installed around the cavity to displace space and save usage of LHe. In addition, we pre-cooled the LHe vessel and the foam ballast with LN2 before starting LHe transfer.

\section{VERTICAL TEST}

\section{TEST-I}

During the first test in June 2002, there was a very steep $\mathrm{Q}$ drop at $3 \mathrm{MV} / \mathrm{m}$, accompanied with strong X-ray bursts (100 R/h measured on beam axis, $1 \mathrm{~m}$ above the cavity equator). Signatures of the reflected power signal was suggestive of multipacting. Simulations confirmed the existence of a two-point multipacting at the observed gradient. $\mathrm{RF}$ processing was pursued but the effort was stopped due to damage occurred to the cable connector underneath the feed-through at the dewar top plate. Condensed water vapor formed a thin layer of ice at the interface between connector dielectric (Teflon) and the cable dielectric (foam), which caused impedance mismatch. This resulted excessive heating at the interface and the foam was burnt into

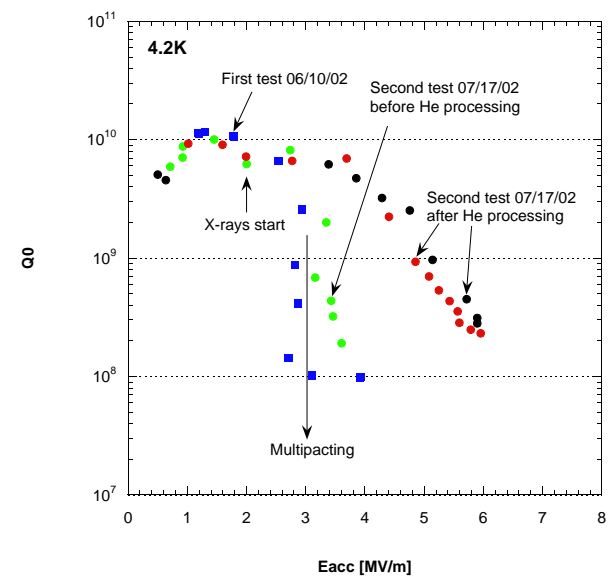

Figure 3: First test results.

carbon, which in turn shorted the inner and out conductors.

The cavity was then warmed up to room temperature and the cable connector was shifted to the outside of the dewar. The second test was again limited by a barrier at 3 $\mathrm{MV} / \mathrm{m}$. Extended RF processing only yielded small improvement. Helium processing was then performed and gradual improvement was obtained. After about 4 hours of helium processing, the accelerating gradient was boosted to $6 \mathrm{MV} / \mathrm{m}$ from $3.5 \mathrm{MV} / \mathrm{m}$. A decrease in x-ray flux rate was observed during helium processing. Ultimately the radiation level reached $100 \mathrm{R} / \mathrm{h}$ at $6 \mathrm{MV} / \mathrm{m}$. We concluded that the limiting mechanism was field emission. These test results are summarized in Fig. 3. It is noted that the low-field Q is already $1 \times 10^{10}$ at $4.2 \mathrm{~K}$, indicating an encouraging film quality.

\section{TEST-II}

After justification of good film quality and conclusion of the field emission limiting mechanism, the cavity was sent back to CERN for another high pressure water rinsing. A fixed input coupler was installed at CERN following cavity rinsing. This practice eliminated further exposure of the cavity inner surface and would be beneficial in reducing particulate contamination, source of field emission, on the RF surface.

As with Test-I results, the multipacting barrier at 3 $\mathrm{MV} / \mathrm{m}$ was observed again. A breakthrough was achieved after a cumulative 3.5 hours of RF processing (in $\mathrm{CW}$ mode). The gradient jumped from $3 \mathrm{MV} / \mathrm{m}$ to $7 \mathrm{MV} / \mathrm{m}$ ! The radiation level was $40 \mathrm{R} / \mathrm{h}$ at $7 \mathrm{MV} / \mathrm{m}$, in contrast to $100 \mathrm{R} / \mathrm{h}$ at $6 \mathrm{MV} / \mathrm{m}$ in Test-I. This indicates that the extra rinsing indeed reduced the number of field emitters. RF processing continued for 4.5 hours, but in a pulsed mode in order to relieve the ceramic of the fixed input coupler from being over heated. Altogether, the accelerating gradient rose from $7 \mathrm{MV} / \mathrm{m}$ to $9.5 \mathrm{MV} / \mathrm{m}$. At this point, the forward power was over $1000 \mathrm{~W}$, which is already twice as high as the coupler power rating. At $9.5 \mathrm{MV} / \mathrm{m}$, the radiation level settled at $30 \mathrm{R} / \mathrm{h}$. Test-II results are summarized 


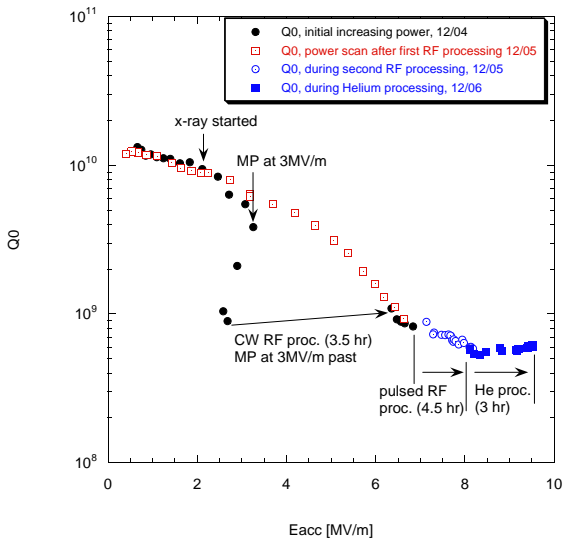

Figure 4: Second test results.

in Fig. 4.

\section{TEST-III}

Test-III was pursued at reduced temperatures. Results are given in Fig. 5. At $2.5 \mathrm{~K}$, the low-field $Q_{0}$ reached

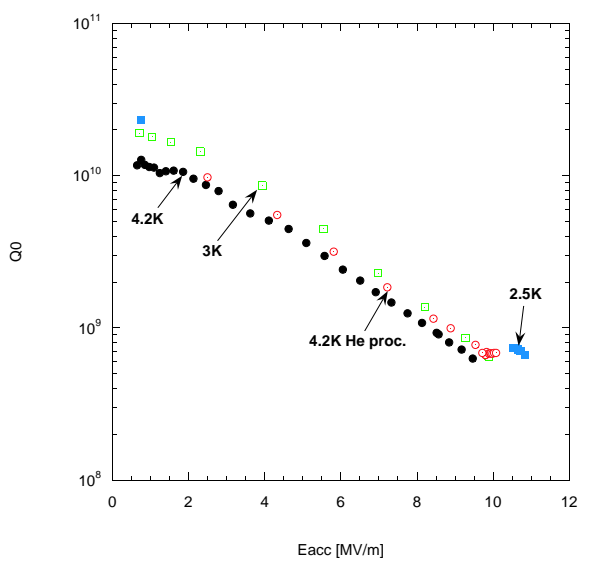

Figure 5: Third test results.

$2 \times 10^{10}$ and the accelerating gradient reached $11 \mathrm{MV} / \mathrm{m}$. Ultimately, the damage power threshold $(1.3 \mathrm{~kW}$ at 200 $\mathrm{MHz}$ ) of the input coupler was reached. For that reason, the data for the measurement at $2.5 \mathrm{~K}$ are obtained only at the two extreme field regions.

\section{MULTIPACTING}

Besides the multipacting barrier at $3 \mathrm{MV} / \mathrm{m}$, a second barrier at $1 \mathrm{MV} / \mathrm{m}$ was also observed. These two barriers show themselves in Fig. 5 as two dips at the corresponding gradients in the $Q\left(E_{\text {acc }}\right)$ curve for $4.2 \mathrm{~K}$. The radiation level also showed peaks at these two gradients. They were sometimes shown as two switches in the reflected power signal (Fig. 6) after RF is turned off. Simulations with the code MULTIPAC [3] confirmed the existence of a multipacting barrier at $3 \mathrm{MV} / \mathrm{m}$ (2-point, first-order). But no barrier is predicted at $1 \mathrm{MV} / \mathrm{m}$, even with an artificially

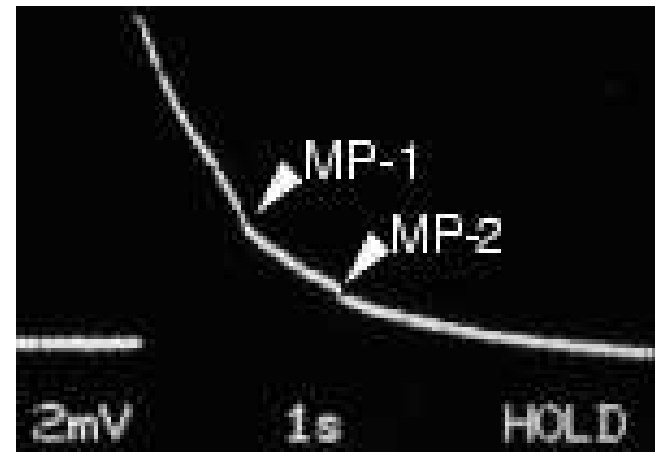

Figure 6: Two multipacting barriers show themselves as two switches, indicated by arrows MP-1 and MP-2, in reflected power signal.

inflated secondary emission coefficient. Nevertheless, the second-order 2-point multipacting is expected at $1 \mathrm{MV} / \mathrm{m}$, since the power level of 2-point multipacting has an order dependence of $1 /(2 \mathrm{~N}-1)$.

As already shown, these multipacting barriers can be processed through within a few hours. In principle, they are not expected to limit the cavity gradients. However, these barriers may become hard and require much longer processing if the cavity surface is contaminated, as evidenced in a recent test of another $200 \mathrm{MHz}$ cavity.

\section{Q-SLOPE}

As shown in Fig. 5, $Q_{0}$ has a strong field dependence. This slope is a result of residual field emission and some intrinsic film characteristics. The fact that $Q_{0}$ changes with temperature indicates that the latter dominates. Analysis, in which field emission contribution is subtracted, shows that the intrinsic Q-slope is steeper than the projected value by an order of magnitude.

\section{CONCLUSION}

A $200 \mathrm{MHz}$ sputtered $\mathrm{Nb}-\mathrm{Cu}$ has been successfully fabricated and tested. The low field $Q_{0}$ reached $1.5 \times 10^{10}$ at $4.2 \mathrm{~K} . E_{a c c}$ reached $11 \mathrm{MV} / \mathrm{m}$, limited by the input coupler. Multipacting barriers at $3 \mathrm{MV} / \mathrm{m}$ and $1 \mathrm{MV} / \mathrm{m}$ can be processed through within a few hours. The film has a stronger Q-slope than projected. This effect needs to be understood in the future.

\section{REFERENCES}

[1] Feasibility Study-II of a Muon-Based Neutrino Source, ed., S. Ozaki, R. Palmer, M. Zisman, and J. Gallardo, BNL-52623 (2001).

[2] H. Padamsee, Proceedings of the 9th workshop on RF superconductivity, 587(1999).

[3] P. Ylä-Oijala, D. Proch, Proceedings of the 10th workshop on RF superconductivity, Tsukuba, Japan (2001). 